\title{
As condições de saneamento no município de Conceição do Araguaia e seus impactos
}

\section{na prevenção da Covid-19}

Sanitation conditions in the municipality of Conceição Do Araguaia and its impacts on the prevention of Covid-19

\section{Condiciones de saneamiento en el municipio de Conceição do Araguaia y sus impactos en la} prevención de Covid-19

Recebido: 15/06/2021 | Revisado: 20/06/2021 | Aceito: 21/06/2021 | Publicado: 05/07/2021

Patricia da Silva Chaves

ORCID: https://orcid.org/0000-0003-3560-5395 Instituto Federal de Educação, Ciência e Tecnologia do Pará, Brasil E-mail: patricia.chaves@ifpa.edu.br

Francisca Nara da Conceição Moreira

ORCID: https://orcid.org/0000-0001-5983-5190 Instituto Federal de Educação, Ciência e Tecnologia do Pará, Brasil E-mail: francisca.moreira@ifpa.edu.br Nellyana Borges dos Santos

ORCID: https://orcid.org/0000-0002-1236-8019 Instituto Federal de Educação, Ciência e Tecnologia do Pará, Brasil E-mail: nellyana.borges@ifpa.edu.br

Ranilson Alves dos Santos

ORCID: https://orcid.org/0000-0003-4445-7830 Instituto Federal de Educação, Ciência e Tecnologia do Pará, Brasil E-mail: ranilson.alves@ifpa.edu.br

\begin{abstract}
Resumo
Para proteger-se do contágio com o vírus foi necessário que a sociedade se adaptasse à uma nova realidade, desenvolvendo novos hábitos sociais e de higiene. Contudo, essa adaptação torna-se difícil quando consideramos as fragilidades estruturais do acesso às mínimas condições de saneamento básico em muitas cidades brasileiras, principalmente nas periferias das capitais e nas cidades dos interiores, como a cidade de Conceição do Araguaia, no estado do Pará. O objetivo deste estudo é criar base de dados passíveis de utilização para auxiliar as tomadas de decisão das secretarias de saúde (municipal e estadual) para as ações de controle perante as medidas de combate à Pandemia referente ao esgoto e a drenagem, tendo em vista a relação do saneamento básico com o contágio da Covid19. A metodologia da pesquisa adotou para o levantamento de dados a aplicação de questionário eletrônico estruturado, com a maioria das questões fechadas, a fim de que se torne possível a transformação de uma série de fatos qualitativos (denominados atributos) numa série de valores quantitativos (denominados variáveis) permitindo assim a análise dos dados. Os resultados evidenciaram que ainda é necessário o investimento na expansão das infraestruturas de drenagem e esgoto como uma estratégia de mitigação da disseminação do SARS-CoV-2 na cidade de Conceição do Araguaia, no Estado do Pará. E, que o acesso ao saneamento básico é de grande importância para as ações de combate a Covid-19.
\end{abstract}

Palavras-chave: Saneamento; Esgoto; Drenagem; Covid-19.

\begin{abstract}
To protect itself from contagion with the virus, society had to adapt to a new reality, developing new social and hygiene habits. However, this adaptation becomes difficult when considering how weaknesses occur in access to minimum basic sanitation conditions in many Brazilian cities, especially on the outskirts of capitals and inland cities, such as the city of Conceição do Araguaia, in the state of Pará. The objective of the study is to create a database that can be used to assist as decision recovery of the health departments (municipal and state) for control actions in the face of measures to combat the pandemic related to sewage and drainage, with a view to relationship between basic sanitation and Covid-19 contagion. The research methodology adopted for data collection the application of a structured questionnaire, with most of the questions closed, in order to make it possible to transform a series of qualitative facts (called attributes) into a series of quantitative values (called variables) thus allowing data analysis. The results showed that investment in the expansion of drainage and sewage infrastructure is still necessary as a strategy to mitigate the spread of SARS-CoV-2 in the city of Conceição do Araguaia, in the State of Pará. And, that access to basic sanitation is of great importance for actions to combat Covid-19.
\end{abstract}

Keywords: Sanitation; Sewer; Drainage; Covid-19. 


\begin{abstract}
Resumen
Para protegerse del contagio con el virus, la sociedad tuvo que adaptarse a una nueva realidad, desarrollando nuevos hábitos sociales y de higiene. Sin embargo, esta adaptación se torna difícil cuando consideramos las debilidades estructurales de acceso a condiciones mínimas de saneamiento básico en muchas ciudades brasileñas, especialmente en las afueras de capitales y ciudades del interior, como la ciudad de Conceição do Araguaia, en el estado de Pará. El objetivo de este estudio es crear una base de datos que sirva de apoyo a la toma de decisiones de los departamentos de salud (municipal y estatal) para acciones de control frente a medidas de combate a la Pandemia en materia de alcantarillado y drenaje, con miras a la relación entre saneamiento básico y contagio de Covid-19. La metodología de investigación adoptó para la recolección de datos la aplicación de un cuestionario electrónico estructurado, con la mayoría de preguntas cerradas, con el fin de permitir transformar una serie de hechos cualitativos (llamados atributos) en una serie de valores cuantitativos (llamados variables) permitiendo así el análisis de datos. Los resultados mostraron que la inversión en la expansión de la infraestructura de drenaje y alcantarillado sigue siendo necesaria como estrategia para mitigar la propagación del SARS-CoV-2 en la ciudad de Conceição do Araguaia, en el estado de Pará. Y, que el acceso al saneamiento básico es de gran importancia para las acciones de combate al Covid-19.
\end{abstract}

Palabras clave: Saneamiento; Alcantarilla; Drenaje; Covid-19.

\title{
1. Introdução
}

A síndrome respiratória aguda, doença denominada Covid-19, causada pelo vírus SARS-CoV-2, possui registros de pacientes infectados desde dezembro de 2019, inicialmente, na China, e, em seguida, se espalhou para outros países, e já provocou milhares de mortes no mundo, instituindo uma Pandemia Global (Skolmowka; Glabska \& Guzek, 2020). A doença chegou ao Brasil em fevereiro de 2020 (Shadmi et al., 2020). Os pacientes infectados apresentam quadros clínicos assintomáticos e sintomáticos, onde os sintomas mais comuns estão vinculados ao trado respiratório, como: tosse, dor na garganta, febre, dificuldade para respirar, perda olfativa e de paladar, podendo evoluir e gerar outras doenças, em casos graves. Além disso, há pacientes que apresentam diarreia devido a presença do vírus no trato gastrointestinal.

Para proteger-se do contágio com o vírus foi necessário que a sociedade se adaptasse à uma nova realidade, desenvolvendo novos hábitos sociais e de higiene. A Organização Mundial da Saúde (OMS) orienta a realização de algumas medidas para a contenção do vírus, que são amplamente divulgadas nos meios de comunicação e devem ser realizadas por todos, como: manter o distanciamento social, lavar as mãos frequentemente, utilizar máscara facial e álcool em gel nas mãos. Contudo, realizar tais medidas torna-se difícil quando consideramos as fragilidades estruturais do acesso às mínimas condições de saneamento básico em muitas cidades brasileiras, principalmente nas periferias das capitais e nas cidades dos interiores, como a cidade de Conceição do Araguaia, no estado do Pará.

Nesse contexto, o saneamento básico é uma pauta que deve ser considerada nas políticas públicas de combate à Pandemia para as ações de controle da disseminação do SARS-CoV-2. De acordo com Aquino (2020), o SARS-CoV-2 pode estar presente em vários ambientes ainda não completamente conhecidos pela comunidade científica. A transmissão do vírus pelo ar atmosférico pode ser afetada por condições climáticas e meteorológicas. As rotas de transmissão fecal precisam também ser consideradas, visto que já foi detectada a presença do vírus em amostras de fezes advindas de pacientes infectados. Como consequência, a presença do agente causador da Covid-19 já foi detectada em esgotos domésticos e águas residuais, conforme as pesquisas de Ahmed et al. (2020), Wang et al. (2020) e Medema et al. (2020).

O saneamento básico é um direito garantido na Constituição e pela Lei no 11.445 (Brasil, 2007). É definido pelo Ministério da saúde (2002) como um conjunto de ações socioeconômicas que têm como objetivo alcançar níveis crescentes de salubridade ambiental, por intermédio de: abastecimento de água potável; coleta e disposição sanitária de resíduos líquidos, sólidos e gasosos; promoção da disciplina sanitária do uso e ocupação do solo; drenagem; controle de vetores e reservatórios de doenças transmissíveis, melhorias sanitárias domiciliares, educação sanitária e ambiental e demais serviços especializados com a finalidade de proteger e melhorar a condição de vida, tanto nos centros urbanos quanto nas comunidades rurais.

Com base nesta definição, entende-se que o saneamento possui uma dimensão transversal, pois se relaciona à 
diferentes dimensões da realidade, tais como a econômica, a partir da sua associação com infraestrutura e desenvolvimento; e ao bem-estar, no tocante à sua articulação com a habitação, meio ambiente e, em termos finalísticos, de seus efeitos sobre a saúde. Como em muitas cidades brasileiras, a cidade de Conceição do Araguaia não apresenta, até o momento, nenhum estudo sobre as condições de saneamento básico e os possíveis impactos à prevenção da Covid-19.

O objetivo do presente artigo é criar base de dados passíveis de utilização para auxiliar as tomadas de decisão das secretarias de saúde (municipal e estadual) para as ações de controle perante as medidas de combate à Pandemia referente ao esgoto e a drenagem, com vistas a relação do saneamento básico com o contágio da Covid-19.

\section{Metodologia}

\section{1 Área de aplicação}

A cidade de Conceição do Araguaia, localizada no Estado do Pará, região norte do Brasil, foi utilizada como área de aplicação da pesquisa.

Inserida na microrregião sul do Pará, na divisa com o Estado do Tocantins, a cidade é banhada pelo Rio Araguaia e não possui estação de tratamento de esgoto e rede de drenagem urbana. E, até 11 de junho de 2021 haviam 3.776 registro de casos confirmados de pessoas infectadas pelo SARS-CoV-2.

De acordo com o IBGE (2020), a cidade possui uma população de 47.991 habitantes e uma área territorial de $5.829,482 \mathrm{~km}^{2}$. O Índice de desenvolvimento humano municipal (IDHM) é 0,64, equivalente ao IDH médio do Estado do Pará que é 0,646 (IBGE, 2010).

\subsection{Estratégia metodológica}

O estudo foi realizado a partir de uma abordagem quantitativa, que se caracteriza por permitir uma abordagem focalizada, pontual e estruturada, sendo a coleta de dados quantitativos realizada através da obtenção de respostas estruturadas (Severino, 2007). Quanto aos procedimentos técnicos, esta pesquisa caracteriza-se como levantamento de dados, conforme explica Gil (2002), pois terá interrogações diretas com pessoas cujo comportamento ou percepção sobre um determinado assunto precisa ser conhecido, afirmando que a característica desse tipo de pesquisa é a interrogação direta das pessoas cujo comportamento se deseja conhecer. Considerando isto, procede-se à solicitação de informações a um grupo de pessoas acerca do problema estudado para, em seguida, mediante análise quantitativa, obterem-se as conclusões correspondentes aos dados coletados.

Os dados serão obtidos por meio da aplicação de questionário eletrônico estruturado, com a maioria das questões fechadas, a fim de que se torne possível a transformação de uma série de fatos qualitativos (denominados atributos) numa série de valores quantitativos (denominados variáveis) permitindo assim a análise dos dados conforme explica Canziani (200, p. 59).

Para muitos pesquisadores inclusive na área das ciências sociais o uso de diversos instrumentos de medida é comum, para que seja possível mensurar a realidade sobre um objeto em estudo, sendo que para realizar esta mensuração Vieira (2008), explica que os pesquisadores precisam desenvolver instrumentos adequados para que as medidas correspondam efetivamente ao que se deseja medir (possuir validade) e para que o erro amostral seja o menor possível (aumentar a confiabilidade) diante dos recursos disponíveis, e desta forma os resultados das medidas seja m um reflexo da realidade.

Considerando as orientações dos órgãos de saúde em função da pandemia, optou-se em realizar o levantamento de dados por meio da distribuição do questionário eletrônico utilizando aplicativo de mensagem instantânea, sendo enviado para diversos grupos de moradores da cidade de Conceição do Araguaia. Esse questionário ficou disponível para o preenchimento por 15 (quinze) dias, onde 156 moradores, de diversos bairros, responderam ao questionário. 
As condições de saúde e de saneamento na cidade de Conceição do Araguaia-Pará diante do cenário da pandemia pela Covid-19, será avaliada a partir das análises das respostas relacionando-as com a interação negativa do sistema de drenagem com efluentes domésticos, da eficiência do escoamento das vias e da obstrução dos dispositivos de drenagem.

\section{Resultados e Discussão}

\subsection{Interação negativa do sistema de drenagem com efluentes de esgoto residencial}

A Covid-19 reforçou a importância do acesso ao saneamento básico para a saúde pública (Caruso \& Freeman, 2020). Estudos indicam o mecanismo de transmissão fecal-oral da doença (Gu; Han \& Wang, 2020; Gwenzi, 2020), fragmentos de RNA viral foram detectados em esgotos de algumas localidades onde haviam casos confirmados de pacientes infectados pelo SARS-CoV-2 (Peccia et al., 2020; Prado et al., 2020). Considerando isto, é importante analisar a infraestrutura das cidades quanto a interação das águas pluviais com as águas servidas dos esgotos residenciais.

Conforme Tucci (2008), a rede de esgoto pode ser combinada (sanitário e pluvial num mesmo conduto) ou separada (rede pluvial e sanitária separada). A legislação estabelece o sistema separador, mas na prática isso não ocorre em razão das ligações clandestinas e da falta de rede de esgoto sanitário. Por causa da falta de capacidade financeira para implantação da rede de esgoto, algumas prefeituras têm permitido o uso da rede pluvial para transporte do esgoto sanitário, o que pode ser uma solução inadequada à medida que esse esgoto não é tratado.

Conforme o levantamento realizado, $32,7 \%$ das pessoas que participaram da pesquisa informaram que o esgoto doméstico da sua residência é destinado para fossas sépticas (revestidas e impermeabilizadas). As fossas sépticas são unidades de tratamento primário de esgoto doméstico, que irá tratar os efluentes de esgoto com objetivo de devolvê-la para o meio ambiente com um menor impacto ambiental. Contudo, essas fossas não tratam por completo as águas advindas dos esgotos sanitários, nem substituem as Estação de Tratamento de Esgoto (ETE). Destaca-se que no município de Conceição do Araguaia não existe ETE.

Ainda de acordo com o levantamento, $28,2 \%$ das pessoas responderam que não sabem informar qual a destinação do esgoto da sua residência, 24,4\% informaram que seu esgoto é destinado para fossa negra (sem revestimento, sumidouro) e $14,7 \%$ responderam que seu esgoto corre a "céu aberto" ou é destinado para rios e córregos, sem tratamento.

Destaca-se que cidades que não detém sistemas de tratamento de esgoto, cujo os dejetos humanos são despejados nos rios; rios esses utilizados para pesca, banhos, lavagem de roupas, práticas religiosas e lúdicas - esses despejos são condições para a proliferação da Covid-19, pois é possível que ocorra a transmissão do vírus por via "fecal-oral”. A exposição a um ambiente contaminado com fezes humanas pode causar "transmissão da mucosa fecal" quando indivíduos tocam a boca, nariz ou olhos com mãos contaminadas (Tian et al., 2020).

A disposição adequada dos esgotos é essencial à proteção da saúde pública e do meio ambiente. "Não saber para onde vai o esgoto" ou possuir o esgoto da sua residência a "céu aberto" pode evidenciar a falta de informação da população quanto a importância da destinação adequada e do tratamento dos efluentes do esgoto domésticos, pois abre uma infinidade de possibilidades destinação, como por exemplo para o sistema de drenagem, o que pode aumentar a possibilidade com contágio de doenças.

\subsection{Obstrução dos Dispositivos de Drenagem por Resíduos Sólidos}

Um dos principais problemas enfrentados pela sociedade contemporânea é a crescente produção de resíduos sólidos que por vezes afetam os sistemas de drenagem urbana ocasionando degradação ambiental, social e econômica do município. Em casos pandêmicos, limpeza urbana e manejo de resíduos sólidos, garantir a salubridade do meio é essencial para a saúde 
Research, Society and Development, v. 10, n. 8, e7610817191, 2021

(CC BY 4.0) | ISSN 2525-3409 | DOI: http://dx.doi.org/10.33448/rsd-v10i8.17191

humana. Sendo imprescindível realizar o manejo adequado dos resíduos (ABES, 2020), visto que eles permanecem por até nove dias, sob temperatura ambiente, em superfícies inanimadas (Kampf et al., 2020). Considera-se que os riscos de contaminação torna-se mais expressivos em áreas onde há precariedade ou ausência da prestação coletiva dos serviços de gerenciamento de resíduos (Araújo \& Silva, 2020)

Estudos recentes associam a permanência do vírus ao tipo de superfície, à temperatura do ambiente, à umidade relativa do ar e à cepa do vírus (Kampf et al., 2020; Who, 2020; Nghiem et al., 2020). Estes autores esclarecem que a persistência do SARSCoV-2 varia de 2 a 9 dias em diferentes superfícies, tais como papelão (24h), aço inoxidável (72h), alumínio (5 dias), papel (5 dias) e plástico ( 9 dias).

De acordo com o levantamento realizado, na cidade de Conceição do Araguaia apenas $48,10 \%$ das vias públicas possuem dispositivos de micro drenagem, desde percentual 10,3\% são bocas de lobo, 33,3\% são sarjetas e 4,5\% são poço de visita. Além disso, 2,6\% das vias são atendidas com o sistema de macrodrenagem, onde são atendidas por canal de drenagem. Entretanto, 49,3\% dos pesquisados informaram que não existe ou desconhecem os dispositivos de drenagem que existem nas suas ruas. Sabe-se que a cidade não possui nenhum tipo de tratamento para as águas residuais advindas da drenagem urbana, onde parte desta é encaminhada diretamente para o rio.

Ainda conforme o levantamento, $55,8 \%$ dos dispositivos de drenagem existentes nas ruas dos participantes da pesquisa não recebem limpeza constantemente, $6,4 \%$ informaram que os dispositivos recebem limpeza e 37,8\% não souberam informar. Sabe-se que a falta de limpeza dos dispositivos pode influenciar na obstrução dos mesmos, estando os sistemas de drenagem e de gestão de resíduos interligados, visto que os resíduos obstruem as galerias do sistema coletor de águas pluviais das cidades durante as chuvas, ampliando os efeitos das enchentes e a disseminação de doenças de veiculação hídrica, como a Covid-19, caso haja interação com as águas residuais do esgoto residencial.

A eficácia do sistema de drenagem depende da gestão e o gerenciamento dos resíduos sólidos. A gestão dos resíduos por meio da eficiência da limpeza das ruas e da programação eficiente quanto à limpeza antes dos dias chuvosos é essencial para reduzir a disseminação de doenças transmissíveis, como a Covid-19 (Mol \& Caldas, 2020). Segundo Nigro et al. (2004), a compreensão das relações entre saneamento, saúde pública e meio ambiente constitui etapa importante no planejamento integrado, permeando ou incluindo questões de drenagem urbana e resíduos sólidos.

\subsection{Eficiência do Escoamento das Vias Urbanas}

Os participantes da pesquisa responderam sobre a frequência da ocorrência de alagamentos nas ruas em que moram. De acordo com o levantamento, $35,9 \%$ das pessoas informaram que na sua rua nunca ocorrem alagamentos e $31,4 \%$ informaram que ocorre raramente. Este fato pode estar ligado a pavimentação do tipo "bloquete" existente em grande parte das ruas do município de Conceição do Araguaia. Esse tipo de pavimentação favorece a infiltração das águas pluviais no solo, diminuindo o volume de água do escoamento superficial e como isso, diminuindo ou sanando os problemas de enchentes e alagamentos.

Ainda conforme o levantamento, $32,7 \%$ das pessoas informaram que frequentemente ocorre alagamentos nas suas ruas. Explica-se que, quando o sistema de drenagem não cumpre a sua função de escoamento das águas pluviais para locais adequados, pode propiciar alagamentos ou empoçamentos e a proliferação de vetores causadores de algumas doenças de veiculação hídrica, como a dengue, a febre amarela, a malária, a leishmaniose, e a Covid-19, quando há interação deste sistema com o sistema de esgoto (Ahmed et al., 2020; Wang et al., 2020). 
Research, Society and Development, v. 10, n. 8, e7610817191, 2021

(CC BY 4.0) | ISSN 2525-3409 | DOI: http://dx.doi.org/10.33448/rsd-v10i8.17191

\section{Conclusão}

O acesso ao saneamento básico é de grande importância para as ações de combate a Covid-19. Os dados levantados apresentados neste trabalho apontam que ainda é necessário o investimento na expansão das infraestruturas de drenagem e esgoto como uma estratégia de mitigação da disseminação do SARS-CoV-2 na cidade de Conceição do Araguaia, no Estado do Pará.

O saneamento de qualidade está associado a menores números de transmissão do vírus. Considerar como mecanismo de transmissão a via fecal-oral da doença é necessário para auxiliar as tomadas de decisão das secretarias de saúde (municipal e estadual) para as ações de controle perante as medidas de combate à Pandemia, considerando a disseminação pelas águas residuárias de esgoto e drenagem.

Diante das análises dos resultados conclui-se que, a disposição adequada dos esgotos é essencial à proteção da saúde pública e do meio ambiente. A falta de informação da população quanto a importância da destinação adequada e do tratamento dos efluentes do esgoto domésticos, abre uma infinidade de possibilidades destinação, como por exemplo para o sistema de drenagem, o que pode aumentar a possibilidade com contágio de doenças. Ressalta-se que as fossas não tratam por completo as águas advindas dos esgotos sanitários, nem substituem a Estação de Tratamento de Esgoto (ETE), a qual não existe no município de Conceição do Araguaia.

Sugere-se para trabalhos futuros, a coleta de amostras de águas residuárias de esgoto e drenagem para verificação da presença do RNA do SARS-CoV-2 e outros agentes patogênicos. Pois, a detecção antecipada de um patógeno associado ao trabalho de equipes multidisciplinares acarreta em melhorias à prática da vigilância epidemiológica, auxiliando na tomada de decisões na Saúde Única - união indissociável entre a saúde humana e ambiental.

\section{Referências}

ABES (2020). Associação Brasileira de Engenharia Sanitária e Ambiental. O impacto da pandemia pela COVID-19 na gestão dos resíduos sólidos urbanos: situação das capitais brasileiras. Pesquisa 2.2, Síntese de Resultados. http://abes-dn.org.br/wpcontent/uploads/2020/08/Pesquisa-ABES-2.1-PandemiaCOVID-19-RSU-Capitais26.8.2020-2.pdf.

Ahmed, W. et al. (2020). First confirmed detection of SARS-CoV-2 in untreated wastewater in Australia: a proof of concept for the wastewater surveillance of COVID-19 in the community. Science of The Total Environment. 728, 1-8. http://10.1016/j.scitotenv.2020.138764.

Aquino, D. S. (2020). Influência do acesso a saneamento básico na incidência e na mortalidade por COVID-19: análise de regressão linear múltipla nos estados brasileiros. Revista Thema. 18(ESPECIAL), 319-331. https://doi.org/10.15536/thema.V18.Especial.2020.319-331.1798

Araújo, E. C. S. \& Silva, V. F. A. (2020). Gestão de Resíduos Sólidos em Época de Pandemia do COVID-19. GeoGraphos. 11(129), 192-215. https://doi.org/10.14198/GEOGRA2020.11.129.

Brasil. Lei n. 11.445/07, de 05 de janeiro de 2007. (2007). Estabelece as diretrizes nacionais para o saneamento básico, cria o Comitê Interministerial de Saneamento Básico. Brasília, DF. http://www.planalto.gov.br/ccivil_03/_ato2007-2010/2007/lei/111445.htm.

Brasil. (2002). Ministério da Saúde. Programa Saneamento Básico. http://bvsms.saude.gov.br/bvs/publicacoes/saneamento.pdf

Canziani, J. R. F. (2001). Assessoria Administrativa a Produtores Rurais. Tese de Doutorado. Universidade de São Paulo, Escola Superior de Agricultura "Luiz de Queiroz".

Caruso, B. A. \& Freeman, M. C. (2020). Shared sanitation and the spread of COVID-19: risks and next steps. The Lancet. Planetary Health, 4(5), 173. https://doi.org/10.1016/S2542-5196(20)30086-3.

Gil, A. C. (2010). Como elaborar Projetos de Pesquisa (4a ed.). Atlas.

Gu, J., Han, B., \& Wang, J. (2020). COVID-19: Gastrointestinal Manifestations and Potential Fecal-Oral Transmission. Gastroenterology. 158 (6), 15181519. https://doi: 10.1053/j.gastro.2020.02.054.

Gwenzi, W. (2020). Leaving no stone unturned in light of the COVID-19 faecal-oral hypothesis? A water, sanitation and hygiene (WASH) perspective targeting low-income countries. Science of The Total Environment. https://doi.org/10.1016/j.scitotenv.2020.141751.

IBGE. (2021). Conceição do Araguaia. Instituto Brasileiro de Geografia e Estatística (IBGE). https://www.ibge.gov.br/cidades-e-estados/pa/conceicao-doaraguaia.html.

IBGE. (2010). Cidades e estados. Instituto Brasileiro de Geografia e Estatística (IBGE). https://www.ibge.gov.br/cidades-e-estados/pa.html 
Research, Society and Development, v. 10, n. 8, e7610817191, 2021

(CC BY 4.0) | ISSN 2525-3409 | DOI: http://dx.doi.org/10.33448/rsd-v10i8.17191

Kampf, G., Todt, D., Pfaender, S. \& Steinmann, E. (2020). Persistence of coronavirus on inanimate surfaces and their inactivation with biocidal agents. Journal of Hospital Infection. 104(3), 246-51. https://doi.org/10.1016/j.jhin.2020.01.022. 2020.

Medema, G., Heijnen, L., Elsinga, G., Italiaander, R. \& Brouwer, A. (2020). Presence of SARS-Coronavirus-2 RNA in sewage and correlation with reported COVID-19 prevalence in the early stage of the epidemic in the Netherlands. Environmental Science \& Technology Letters, 7, 511-516. https://doi.org/10.1021/acs.estlett.0c00357

Mol, M. P. G., \& Caldas, S. (2020). Can the human corona virus epidemical so spread through solid waste? Waste Management \& Research, 38(5), 485-486. https://doi.org/10.1177/0734242X20918312.

Nghiem, L. D., Morgan, B., Donner, E., \& Short, M. D. (2020). The COVID-19 pandemic: considerations for the waste and waste water services sector. Chemical and Environmental Engineering, (1), 1000006. https://doi.org/10.1016/j.cscee.2020.100006.

Nigro, C. D, Bernardi, J. L., Brito, M. C. C, Garcias, C. M., \& Aisse, M. M. (2004). Elementos norteadores para a gestão da drenagem urbana e dos resíduos sólidos urbanos incorporados à gestão das cidades: aplicação a cidade de Quatro Barras/PR. Anais International Congress on Environmental Planning and Management Environmental Challenges of Urbanization/ Paper - Environmental quality, Brasília, Brasil.

Peccia, J. et al. (2020). SARS-CoV-2 RNA concentrations in primary municipal sewage sludge as a leading indicator of COVID-19 outbreak dynamics. medRxiv. https://doi.org/10.1101/2020.05.19.20105999.

Prado, T. et al. (2020). Preliminary results of SARS-CoV-2 detection in sewerage system in Niterói municipality, Rio de Janeiro, Brazil. Memórias do Instituto Oswaldo Cruz, 115, 307 e200196. https://doi.org/10.1590/0074-02760200196.

Severino, A. J. (2007). Metodologia do trabalho científico, Cortez.

Slolmowska, D., Glabska, D., \& Guzek, D. (2020). Hand Hygiene Behaviors in a Representative Sample of Polish Adolescents in Regions Stratified by COVID-19 Morbidity and by ConfoundingVariables (Place-19 Study): Is There any Association? Phathogens. 9(12), 22. https://doi.org/10.3390/pathogens9121011.

Shadmi, E. et al. (2020). Health equityand COVID-19: global perspectives. International Journal for Equity in Health, 19(104), 16. https://doi.org/10.1186/s12939-020-01218-z.

Tian et al. (2020). An investigation of transmission control measures during the first 50 days of the COVID-19 epidemic in China. Science. 368(6491), 638642. https://doi.org/10.1126/ Science.abb6105.

Tucci. (2008). Águas Urbanas. Estudos Avançados, 22 (63). Dossiê Água. https://doi.org/10.1590/S0103-40142008000200007.

Vieira, K. M. \& Dalmoro, M. (2008). Dilemas na Construção de Escalas Tipo Likert: O Número de Itens e a Disposição Influenciam nos Resultados? http://www.anpad.org.br/admin/pdf/EPQ-A1615.pdf.

Wang, J. et al. (2020). SARS-CoV-2 RNA detection of hospital isolation wards hygiene monitoring during the Coronavirus Disease 2019 outbreak in a Chinese hospital. International Journal of Infectious Diseases. 94, 103-106. https://doi.org/10.1016/j.ijid.2020.04.024.

Who. (2020). Water, sanitation, hygiene, and waste management for SARS-CoV-2, the virus that causes COVID-19. Interim Guidance, World Health Organization. https://www.who.int/publications/i/item/WHO-2019-nCoV-IPC-WASH-2020.4. 